\title{
A New Buffer Monitoring Approach Based on Earned Value Management Concepts
}

\author{
Mehrasa Mosallami, and Siamak Haji Yakhchali \\ Department of Industrial Engineering, College of Engineering, University of Tehran, Tehran, Iran.
}

\begin{abstract}
Critical chain and buffer management has known to present a viable approach for constructing a robust project schedules and to propose a new control tool for monitoring the project progress and detecting the project deviations timely. In this paper the focus lies on buffer management system, more precisely on determination of allowable buffer consumption pattern, and introduced a new buffer monitoring approach which produced by applying earned value management (EVM) concepts on buffer threshold. We show how the buffer monitoring system can be complementary with EVM concepts and can produce a more reliable project control process which correctly differentiate the accepted and unaccepted deviations.
\end{abstract}

Keywords: Critical chain, buffer management, allowable buffer consumption pattern, earned vale management.

\section{Introduction}

While delivering project on time is a critical factor for project success but late project delivery is nowadays still commons. According to the annual global survey of PMI, only $49 \%$ of projects have been completed timely, therefore there are projects which have been delivered beyond the pre-defined time objectives [16]. Hence a proper approach for managing project should be improved to meet the project predefined objectives.

Critical chain project management outcome the application of theory of constraint (TOC) was proposed by Goldartt in 1997 [5]. It has shown to provide a new technique to construct a proper project schedule with considering resource constraints and make robust schedule by inserting various types of buffers (project buffer, feeding buffers and resource buffers). Besides proposing a new scheduling technique, it has also introduced a new control system to improve the schedule performance during project execution phase to meet predefined deadline. The mechanism of proposing control system is based on monitoring the buffers, and so warning signals would be generated when the project deadline is expected to be exceeded by monitoring buffers. Therefore the size of buffers and how they are monitored, are critical factors in successful application of CCPM [10] and [8]. The main aim of this paperis based on the section of control system and improving the buffer monitoring system. In this way the concepts of EVM were applied and new tolerance limits for buffer consumption in each phase of project were introduced.

The paper is organized as follows, section 2 provides some studies about critical chain and buffer management. In section 3, a popular buffer management system is introduced and a brief description of that is presented. Section 4 presents EVM/ES method which has the main role in our approach. Our new approach is showed and cleared in section 5 and finally in the last section, the conclusion and future research directions are drawn.

\section{Literature Review}

The idea of critical chain and buffer management was introduced by Goldartt in 1997 at first and become a new researching subject in academic world (for example, [17], [18], [20] and [14]). In [6], authors tried to represent the capability of critical chain method and checked the merits and pitfalls of that. The critical chain method was developed not only in academic societies but also some companies began to apply it in project management [4]. In [1], by a case study, was shown that by application of critical chain method in company, quality and safety of works were maximized, and time and cost were minimized. 
As mentioned before, the size of buffers is one of the critical factors in successful application of CCPM, so the vast majority of critical chain management researches is based on the determination of the proper buffer size. . Two popular and pioneer buffer sizing techniques named, cut a paste method (C\&PM) and route and square error method (RSEM) that respectively mentioned in [5] and [13]. Then in [19], were proposed two new adaptive buffer sizing procedures which seem to be more reliable than previous methods. Other researchers focused on different aspects of project and organizations and considered other conditions affected on the size of buffers. A detailed study of this section is outside the scope of this paper and readers can refer to some researches, for example, [21], [2] and [9].

The main aim of this paper is related to the section of buffer monitoring system, therefore the rest of this section is about the literature of buffer monitoring system.

The first buffer monitoring system was introduced by Goldartt (1997) and the green-yellow- red monitoring system was proposed. This system divides the project buffer in to three parts which represents the three region of decision zones. In this system, two constant action thresholds are determined which distinguish these zones [5]. The second buffer monitoring system which is described in [11], was not considered constant action threshold. In this approach, again, three region of decision zones were considered but supposed that the two action threshold of buffer are linearly allocated during the project. In [7], author put forward a new CC/BM-based schedule monitoring procedure that evaluates the probability of successful project completion relative to the cost of crashing and that determines when to expedite which activity in a cost-effective manner. in [8] author incorporated the activity sensitivity measure into the buffer monitoring process, enabling the management team to estimate the risk of project delays on the whole and to identify high-risk activities in particular when taking expediting actions. In [3] the application of buffer concept from critical chain management in earned value management/ earned schedule (EVM/ES) is illustrated and linearly tolerance limits were proposed for the EVM/ES schedule performance metrics SPI ( $t$ ) and SV ( $t$ ). In the other research, authors set tolerance limits for EVM/ES schedule performance metrics EVM/ES by allocating project buffer over the different project phases and new metrics have been developed [12].

\section{Buffer Monitoring System}

Buffer monitoring system is a kind of approach for controlling project. This approach uses buffers to measure project performance. The existing buffer monitoring system mainly follows the practice established by Goldartt (1997) for production operation. In this approach, three regions with static action threshold were proposed, in [11] author questioned Goldratt's static monitoring notion, and he recommended the two buffer trigger lines to vary linearly over the planned duration of the project considering the fact that the uncertainty might decrease as the project progresses. This approach is known to RBMA and has been described comprehensively and accurately in [7]. We choose this approach as the representative method to show the mechanism of buffer monitoring system.

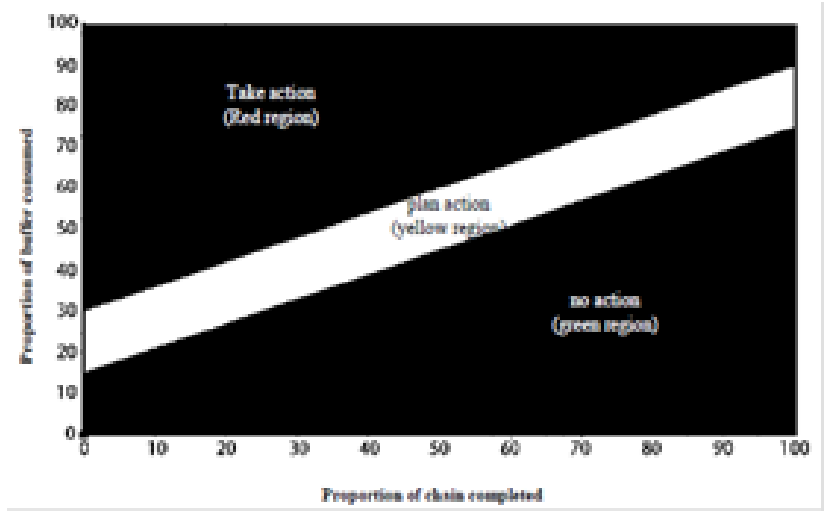

Fig 1: buffer threshold 
According to this system, the buffer is divided into three regions and buffer trigger points are set to activate management actions. By comparing the actual project implementation against the baseline schedule at time instant $\mathrm{t}$ (see Figure 1), one can easily calculate how much of the buffer is consumed and the region of system said, determined. If buffer consumption is negative or in green region, no action is recommended and the remaining buffer can be enough to the rest of the project. In yellow region management team should plan action to speed of the execution of remaining task and finally in red region, management team should immediately take action to recover buffer.

\section{Earned Value Management}

Earned value management is a methodology used to measure and communicate the real physical progress of a project and to integrate the three critical elements of project (time, cost and scope). EVM uses three key metrics to measure the progress of a project, namely planned value (PV), earned value (EV) and actual cost (AC). In figure 2, the graphic view of EVM data is presented. The curve shows the cumulative amount of value that is planned at every period during life cycle of project (according to PV curve). EV is periodically measured and presented a measure of the work performed, expressed in terms of the budget authorized for that work. AC is also periodically measured and presented the realized cost incurred for the work performed on an activity during a specific time period. Based on these three metrics, the status of project schedule and cost performance would be determined [12] and [15].

In the next section the application of EVM basics in proposed buffer monitoring system has been shown.

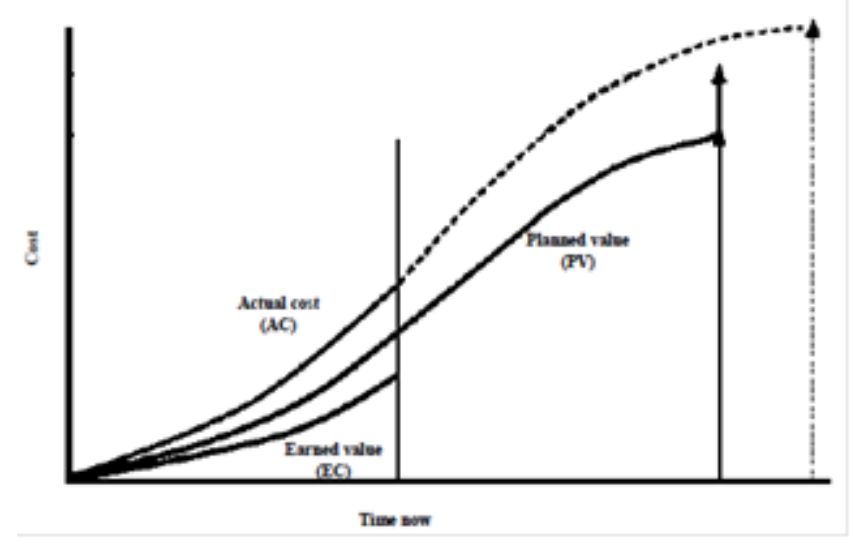

Fig 2: EVM basic concepts: chart form

\section{Integration of Buffer Monitoring System and Earned Value Management}

As mentioned before in literature, authors in [3] and [12] applied buffer management concept in EVM method to produce a new tolerance limits for SPI (t) and SV (t) metrics. In this section, we applied EVM concepts to construct an improved buffer monitoring system. Traditionally, the allowable buffer consumption is set linear with the project duration. More precisely, at $\mathrm{x} \%$ of project make span, $\mathrm{x} \%$ of predefined buffer is allowed to consume. In this assumed pattern, the amount of work during project was not considered, so the efficiency of this pattern in real project application would be decreased. To cover this defect, we decide to improve the pattern of allowable buffer consumption and consider the amount of work in each stage of project in designing the allowable buffer consumption pattern.

As mentioned before, EVM is a methodology used to measure and communicate the real physical progress of a project. PV curve shows the planned amount of work during project execution. So in order to determine an allowable buffer consumption in each stage of project execution which considers the amount of work planned, we use PV curve and illustrate buffer consumption pattern based on PV curve. In figure (3) our new approach for buffer consumption pattern is presented. 


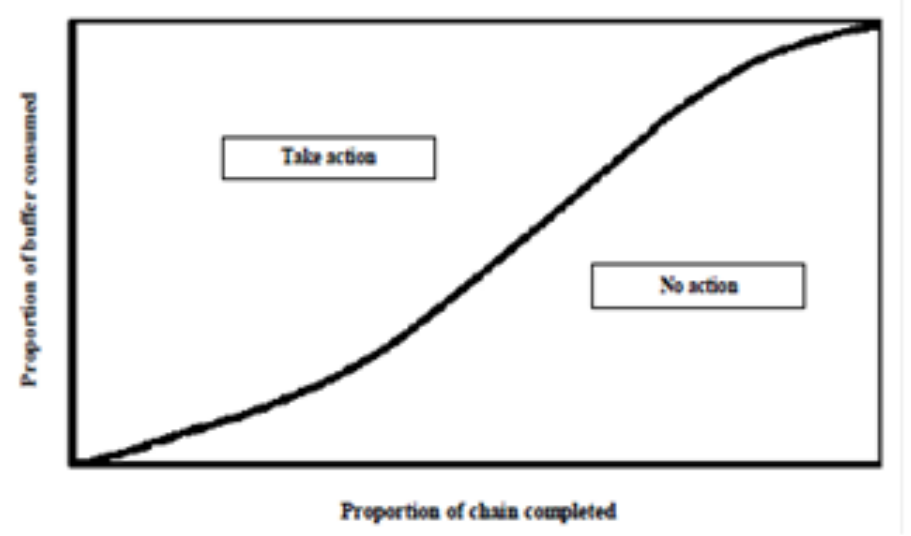

Fig 2: a new approach of buffer monitoring system

Unlike the common practice that the buffer divided to three region (green, yellow and red) and two action threshold were determined, our approach contains one buffer threshold and two regions. If the region of buffer consumption is below the buffer threshold, it means that the remaining buffer can be enough to protect the variation of the unfinished activities, so no action is recommended. But if buffer consumption is over buffer threshold, it means that buffer is consumed more than plan, and there is high probability that remaining buffer is not sufficient to protect the delay of project. So management team should focus more and be ready to take corrective actions.

\section{Conclusion}

Buffer management is a kind of project control tool which uses buffer to protect project performance. The main aim of this paper is, present an improved buffer consumption pattern which is more reasonable and applicable in real projects. More precisely we highlight the amount of work to determine the allowable buffer consumption in each stage of project. For this purpose, we introduced a new buffer consumption pattern which is produced by integrating with EVM method. We think our proposed approach can cause a new way for future study in critical chain and buffer management area. This idea should be completed (determining the applying steps of this method) and compared to the previous methods to testify its effectiveness.

\section{References}

[1] M. Bevilacqua, "Critical chain and risk analysis applied to high-risk industry maintenance: a case study," International journal of project management, vol. 27, no. 4, pp. 419-432, 2009.

[2] L. Bie, N. Cui, and X. Zhang, "Buffer sizing approach with dependence assumption between activities in critical chain scheduling," International Journal of Production Research, vol. 50, pp. 7343-7356, 2012.

[3] J. Colin, M. Vanhoucke, “A comparition of the performance of various project control methods usinf earned value management systems, ” Expert Systems with Applications, vol. 42, no. 6, pp. 3159-3175, 2014.

[4] N. Cui, W. Tian, L. Bie, "Rescheduling after inserting the buffer in the critical chain scheduling," IEEE, 2010.

[5] E. M. Goldratt, Critical chain: A business novel: North River Press Great Barrington, MA, 1997.

[6] C. Herreloen, R. Leus, "On the merits and pitfalls of critical chain scheduling," Journal of operations management, vol. 19, no. 5, pp. 559-577, 2001.

[7] X. Hue, N. Cue, E. Demeulemeester, "Effective expediting to improve project due date and cost performance through buffer management," International journal of production research, vol. 53, no. 5, pp. 1460-1471, 2015.

[8] X. Hu, N. Cui, E. Demeulemeester, and L. Bie, "Incorporation of activity sensitivity measures into buffer management to manage project schedule risk," European Journal of Operational Research, vol. 249, pp. 717-727, 2016. 
[9] H. Iranmanesh, F. Mansourian, S. Kouchaki, "Critical chain scheduling: a new approach for feeding buffer sizing," International journal of operational research, vol. 25, no. 1, pp. 114-130, 2016.

[10] M. A. Khemakhem, H. Chtourou, "Efficient robustness measures for the resource-constrained project scheduling problem, ”International Journal of Industrial and Systems Engineering, vol. 14, no. 2, pp. 245-267, 2013.

[11] L. P. Leach, Critical chain project management. London: Artech house, 2005.

[12] A. Martens, M. Vanhoucke, “A buffer control method for top-down project control," European Journal of Operational research, vol. 262, no. 1, pp, 274-286, 2017.

[13] R. C. Newbold, Project management in the fast lane-applying the theory of constraint. Boca Raton: The St. Lucie Press, 1998.

[14] W. Peng, M. Huang, "A critical chain project scheduling method based on differential evolution algorithm, ” International Journal of Production Research, vol. 52, no. 13, pp. 3940-3949, 2014.

[15] Project Management Institute, Practice standard for earned value management. Pennsylvania: project management institute, 2011.

[16] Project Management Institute, PMI's Pulse of the Profession-The High Cost of Low performance, technical report, PMI, 2016.

[17] M. Rabbani, S.M.T. Fatemi Ghomi, F. Jolai, N.S. Lahiji, “A new heuristic for resource-constrained project scheduling in stochastic networks using critical chain concept," European Journal of Operational Research, vol. 176, pp. 794-808, 2007.

[18] J. A. Ricketts, Reaching the Goal. Westford, MA: IBM Press, 2008.

[19] O. L. Tukel, W. O. Rom, S. D. Eksioglu, “An Investigation of Buffer Sizing Techniques in Critical Chain Scheduling," European Journal of Operational Research, vol. 172, no. 2, pp. 401-416, 2006.

[20] M. Vanhoucke, Project Management with Dynamic Scheduling. Berlin: Springer, 2012.

[21] K. Woo, S. Park, S. Fujimura, "Real-time buffer management method for DBR scheduling," International Journal of Manufacturing Technology and Management, vol. 16, nos. 1/2, pp. 42-57, 2009. 